\title{
MICROMACHINED MICROBEAMS MADE FROM POROUS SILICON \\ FOR DYNAMIC AND STATIC MODE SENSING
}

\author{
Xiao Sun ${ }^{1,2}$, Giacinta Parish $^{2}$ and Adrian Keating ${ }^{1}$ \\ ${ }^{1}$ School of Mechanical and Chemical Engineering, University of Western Australia, 35 Stirling \\ Hwy, Crawley, Western Australia 6009, Australia; \\ ${ }^{2}$ School of Electrical, Electronic and Computer Engineering, University of Western Australia, 35 \\ Stirling Hwy, Crawley, Western Australia 6009, Australia
}

Xiao Sun

Email: xiao.sun@uwa.edu.au

Tel: +61(8) 64883745

*Corresponding author

Giacinta Parish

Email: giacinta.parish@uwa.edu.au

Adrian Keating

Email: adrian.keating@uwa.edu.au; 
Abstract: Through a controlled variation of the applied current during porous silicon formation, newly developed processes enable previously unattainable structural integrity of all-mesoporous silicon microelectromechanical systems (MEMS) structures. Such structures are desirable for applications such as sensing where the large surface area and low Young's modulus of the high porosity layer enable ultra-high sensitivity detection of adsorbed species. In this work, micromachined all-mesoporous silicon microbeams were released, allowing both the dynamic and static sensing modes to be studied using such porous structures. Resonant frequencies (50$250 \mathrm{kHz}$ ) of released doubly clamped porous silicon microbeams were measured, allowing mechanical properties to be extracted. Static mode sensing of vapour at the $1100 \mathrm{ppm}$ level was also performed, with the released porous silicon cantilevers showing a significant $6.5 \mu \mathrm{m}(3.7 \%$ of a $175 \mu \mathrm{m}$ beam length) and repeatable deflection after exposure.

Keywords: porous silicon, frequency, sensing, vapor 


\section{INTRODUCTION}

Porous silicon (PS), a form of silicon that has nanopores introduced into its microstructures, is generally formed by electrochemical anodisation of crystalline silicon in a HF/Ethanol solution [1]. PS has been exploited in various sensing applications utilising solvents for proof of concept, with the transduction based on changes in optical reflection [2, 3], diffraction [4], waveguide transmission [5], photoluminescence [6] or electrical characteristics [7]. These studies have recognised that the large surface area [8] of the porous film significantly enhances the sensitivity, enabling the capture of biological molecules $[9,10]$ or adsorption of gas/liquid $[11,12]$ at very low detection limits. In addition, for optical applications the tuneable refractive index of the porous films [13] makes PS an excellent platform for fabricating optical structures with controllable reflectance or transmittance [14-19]. However, despite the above published preliminary studies, to date no viable uniform porosity PS-based sensor that is compatible with microelectronic fabrication methods is available to support a scalable, low cost technology.

Sensing using micromachined devices, also referred to microelectromechanical systems (MEMS), has opened up opportunities for a new class of sensors which can be electrically actuated and electrically/optically integrated [20]. These sensors are typically microbeams made from bulk (non-porous) structural layers, which have been released from the underlying substrate, allowing them to deflect or vibrate in response to environmental changes. To achieve the lowest zepto-gram $\left(10^{-21}\right)$ detection limits [21], these MEMS microbeams must operate at high frequency, which requires very small microbeam dimensions. However since these sensors can only respond to adsorption on the exposure surface, reducing size to achieve high frequency operation also limits the available surface area. We have recently demonstrated released all-PS MEMS made from a porous silicon structural layer with controllable porosity [22, 23] where the 
porosity control was achieved through varying the current during anodization. This process opens new opportunities to increase the ultimate limit of detection of these micromachined sensors through the increased surface area of the films. Fernandez et al. [24] found that even a thin porous silicon on a polysilicon cantilever showed significant improvement due to the increased surface area for species attachment.

To achieve chemical and gas sensing through adsorption, MEMS sensors operate via one of two modes, namely static mode (typically detection of height change) [20] and dynamic mode (typically detection of motion/resonance). In the static mode, the deflection of the microbeam due to stress changes induced by analyte adsorption is measured using optical readout techniques which enable extremely high precision sensitivity to be achieved. Deflection due to the mass change associated with adsorption is generally considered negligible since inertial (gravitational) effects depend on density and volume, which for bulk materials contribute little at the microscale. Whilst static mode is very sensitive and often used in AFM readouts, the size of the read-out system limits the number of MEMS devices that can be addressed simultaneously. In the dynamic mode, measurement of the resonant frequency of the beam is performed, and leveraging integrated electronics and/or optics can allow simultaneous interrogation of a large number of such sensors, providing opportunities for multi-analyte sensing [25]. This mode usually senses the change in the resonant frequency of the beam due to analytes that become adsorbed to the exposed surface. Importantly, the sensitivity of both static and dynamic read-out methods are limited by the exposed MEMS surfaces onto which a species can adsorb/desorb.

In this work, we demonstrate both static and dynamic mode operation of MEMS structures formed using porous silicon, which provides an extremely large surface area for adsorption/desorption of species. The key to achieve this has been the formation of low stress all- 
porous-silicon microbeams. Furthermore these microbeams are fabricated with standard photolithography-based processes, which combined with the underlying silicon platform, provides a path to a scalable, low-cost technology. The outcomes provide significant opportunities for low-cost high sensitivity sensing, beyond that which is possible with existing technologies.

\section{METHOD}

For the PS film fabrication, room temperature anodization was performed on moderately doped p-type (100) silicon wafers with resistivity of $0.08-0.12 \Omega \cdot \mathrm{cm}$. The electrolyte used during anodization was 15\% HF/ethanol solution, and the current density and anodization duration was chosen to achieve the desired porosity $(P)$ and thickness $(t)$ control. For this work the current density during anodization was carefully controlled to create PS films with little or no vertical stress gradient [22], achieving a film with an average porosity $P=73 \pm 1 \%$ and physical thickness of $t=2.5 \pm 0.1 \mu \mathrm{m}$. Under these condition a meso-PS film was achieved with pore sizes ranging from 2-50 nm, as shown in Fig. 1(a)-(b). After formation, the PS film was subsequently annealed in a $\mathrm{N}_{2}$ atmosphere at $600{ }^{\circ} \mathrm{C}$ for $6 \mathrm{~min}$ at $1000 \mathrm{sccm}$. The annealing process is critical as it makes the PS film stable (preventing ageing through oxidation) as well as suitable for direct photolithography processing using alkaline developer [26]. With films formed in this manner, comprehensive micromachining processes including photolithography, inductively coupled plasma reactive ion etching (ICP-RIE), repeated photolithography, electropolishing and critical point drying were able to be applied to successfully achieve a high yield of fully released PS microbeams suspended above the Si substrate. Fig. 2 shows images of fabricated and released (a) PS doubly clamped beams and (b) PS microcantilevers of different length which are curved slightly due to residual stress gradient. Both the doubly clamped beams and microcantilevers 
were fabricated with a designed air gap of approximately $2.5 \mu \mathrm{m}$ which was controlled by the electropolishing duration. Variations in the released height of the beams shown in the inset of Fig. 1 are due to residual stress near the edge and process variations during electropolishing. Larger gaps are possible but require improved anchors and reduced undercut. Full details of these structures and their characterisation have been previously reported [22].

Both of the two previously described major read-out methods, dynamic mode and static mode, were employed in characterising the PS-MEMS structures in this work. In the dynamic mode, measurement of the resonant frequency for the released PS microbeams was carried out with a laser Doppler vibrometer system as schematically illustrated in Fig. 3. The sample was actuated through a piezoelectric element attached to the substrate which was driven by a function generator (Agilent 33220A). The function generator was controlled through a Labview programme to slowly apply a swept sine-wave over a selected frequency range to actuate the sample. The time-domain output of the laser Doppler vibrometer (Polytec OFV-5000) was measured using a digital oscilloscope (Rigol DSO 5014A), which provided a measure of the deflection of the microbeam at each frequency of the function generator. During the measurements, the sample was kept in a vacuum chamber which was maintained at a pressure below $6.0 \times 10^{-3}$ Torr. The vacuum environment was important to eliminate the effect of squeezed film damping [27] which can suppress the resonance of the vibrating beam. However an advantage of our fabrication process is that the air gap under the beam can be controlled by the duration of the electro-polishing release step. Where a gap of more than $10 \mu \mathrm{m}$ can be achieved, squeezed film damping effects are considered negligible, allowing these measurements to be performed in subsequent studies under ambient conditions without the need for a vacuum chamber. 
The laser Doppler vibrometer utilised a differential fibre probe, which provided a measurement and reference laser beam which could be independently positioned on the sample as viewed through the microscope. The reference beam of the laser Doppler vibrometer was reflected off the silicon substrate while the measurement beam was reflected off the PS microbeam. This ensured that the measured signal from the vibrometer was due only to the microbeam displacement induced by the piezoelectric actuator and did not arise from other sources. Both velocity and displacement of the microbeam could be measured in real-time through the vibrometer controller.

During static mode measurements of our sample, the height change of PS microbeams was measured using a non-contact optical profilometer (Zygo NewView ${ }^{\mathrm{TM}}$ 6000). Fig. 4 shows a schematic of the experimental setup in which sensing of isopropanol vapour using a PS microcantilever was carried out. This is the first time vapour sensing using comparable porous micromachined structures has been achieved. Initially the PS microbeam was enclosed on the optical profilometer measurement stage inside a chamber, without vapour, and the height of the PS microbeam was measured as a reference. Subsequently, a drop of isopropanol of fixed volume was deposited near the PS microbeam through a pipette, as shown in Fig. 4(a). The drop of isopropanol $(50 \mu \mathrm{l})$ in the chamber (volume $44.5 \mathrm{~cm}^{3}$ ) resulted in a vapour density of 1100 ppm by volume $\left(1.1 \times 10^{-3} \mathrm{ml} / \mathrm{cm}^{3}, \sim 1.5 \times 10^{-5} \mathrm{~mol} / \mathrm{cm}^{3}\right)$. After $15 \mathrm{~min}$, all the solvent evaporated and was partially adsorbed by the PS microbeam. The cover of the chamber was subsequently opened for immediate measurement of the deflection. The deflection measurements were performed at regular time intervals with the optical profilometer. The height change $(\Delta h)$ of the microbeam after adsorption is illustrated in Fig. 4(b).

\section{RESULTS AND DISCUSSION}




\subsection{Resonant frequency measurement in dynamic mode}

Dynamic measurements in this study were designed to determine the resonant frequency variation with length, allowing Young's modulus $\left(E_{P S}\right)$ and stress $(\sigma)$ of the beam to be extracted. Stress is an important parameter to examine as changes to the stress due to adsorption directly affect the resonant frequency. As such, characterisation of the resonant frequency is essential to validate the sensing platform before adsorption based studies could be performed. The displacement-frequency spectrum of PS doubly clamped microbeams with different lengths $(L)$ was measured as shown in Fig. 5. The all-PS microbeams were fabricated through the processes detailed in Section 2. All microbeams were of the same width $W=20 \mu \mathrm{m}$ and $t=2.5 \mu \mathrm{m}$ thickness, with lengths ranging from $L=200 \mu \mathrm{m}$ to $L=450 \mu \mathrm{m}$. The fundamental resonant frequency $\left(f_{1}\right)$ of each microbeam was identified from the highest peak in the spectrum for each corresponding measurement. The measurement results in Fig. 5 show that the lowest (fundamental) resonant frequency $f_{l}$ decreased with increasing microbeam length. The fundamental mode exhibits a high signal to noise ratio compared with the background noise. While a single resonant peak is expected, in some cases a secondary peak very close to the first is observed. This secondary peak is attributed to the imperfect boundary condition caused by the undercut during electropolishing. As the length increases, a second peak well away from the fundamental mode frequency is observed at higher frequencies, as shown in Fig. 5(c). The second longitudinal mode is expected at 2.5 times the fundamental frequency [28] which is consistent with our measured data in Fig. 5(c) where the measured ratio is 2.3. However as discussed below, beams above $300 \mu \mathrm{m}$ exceed the Euler buckling limit, so that stable oscillation at well-defined harmonic frequencies no longer occurs. This is evident for the $400 \mu \mathrm{m}$ beam measured in Fig. 5(d), for which the ratio of fundamental frequency to the second harmonic is 3.6 , well away from the 
expected value of 2.5 [28]. As reported before, the residual stress present along the axial direction of microbeam will change its resonant frequency [29], thus the measured results and theoretical frequency considering 1.1 MPa tensile stress in the PS film after HF immersion (as reported in our previous work [23]) are compared as shown in Fig. 6. The plot shows that the measured frequency of PS microbeam is consistent with theoretical data, though a small change in stress could result in significant shift of the frequency. Therefore, it is necessary to investigate the effect of residual stress on resonance of PS microbeams.

The known linear relationship between $L^{-2}$ and $f_{l}^{2} L^{-2}$, from the work of Zhang et al. [30], allows the Young's modulus and stress to be extracted from measured data. We have reworked this relationship to provide net effective stress allowing the data to be more directly compared to measured data and comparable Euler buckling stress. This relationship is given by [30]:

$$
\begin{aligned}
& f_{1}^{2} L^{2}=1.057 * \frac{t^{2} E_{P S}}{\rho_{P S} L^{2}}+0.31 * \frac{\sigma}{\rho_{P S}} \\
& \frac{f_{1}^{2} L^{2} \rho_{P S}}{0.31}=3.41 \frac{t^{2} E_{P S}}{L^{2}}+\sigma=\sigma_{m}
\end{aligned}
$$

The first line of Eq. (1) arises from Zhang et al. [29] where $\rho_{P S}$ is the density of PS given by $\rho_{S i}(1-P)$, and $\rho_{S i}$ is the density of silicon $\left(2.31 \mathrm{gm} / \mathrm{cm}^{3}\right)$. The second line transforms the first to provide $\sigma_{m}$ which we define as a net effective stress parameter and is related directly to the measured resonant frequency of each beam through $\sigma_{m}=\frac{f_{1}^{2} L^{2} \rho_{P S}}{0.31}$. Fig. 7 shows the measured data of net effective stress $\left(\sigma_{m}\right)$ as a function of $L^{-2}$ which allows the Young's modulus and stress to be extracted. Importantly we note the data deviates from the expected linear relationship. Also overlaid is the stress which defines the Euler buckling limit for a compressed beam. The point at which $\sigma_{m}$ approaches zero corresponds to the point at which the buckling stress exceeds the mechanical strength (term $3.41 t^{2} E_{P S} / L^{2}$ in Eq. (1)), leading to erratic performance [28]. As a 
result of this limit, high uncertainties exist in the region $L^{-2}<8 \times 10^{-6} \mu \mathrm{m}^{2}$ in Fig. 5, so that only data above these values were used to fit the data. Previous researchers have assumed tensile stress is required in beams for this analysis to work, however compressive stress is permitted up to the Euler buckling limit.

While a stable low tensile stress $(+1.1 \mathrm{MPa})$ is expected from $\mathrm{N}_{2}$ annealed PS film $(P=81 \%)$, HF immersion can degrade the passivation and alter the stress [31]. Because the final process step was electropolishing via HF immersion, it is likely the passivation was degraded, leaving the PS vulnerable to oxidation. As this sample was exposed to air for approximately 3 days during the measurements, oxidation would have been very likely. The presence of a slight compressive stress (decrease in tensile stress) in the PS film is consistent with oxidation. The results of these studies indicate further process improvements are required to improve the performance of these structures when measured using the dynamic mode of operation.

Using this model, the residual stress and Young's modulus of the PS film were extracted, yielding a residual (compressive) stress of $\sigma=-1.00 \pm 0.13 \mathrm{MPa}$, and a Young's modulus $E_{p s}=7.96 \pm 0.01 \mathrm{GPa}$, with a $95 \%$ confidence interval for the uncertainties calculated. The residual stress results in an initial offset of the resonant frequency which is further shifted by adsorption. The shift in frequency from the stress-free state is given by:

$$
\left.\frac{\Delta f}{f_{1}}\right|_{P S}=0.15 * \frac{\sigma L^{2}}{t^{2} E_{S i}(1-P)^{3}}
$$

where this form is valid for small shifts from the resonant frequency $f_{1}$ and the relationship between Young's modulus and porosity used is $E_{P S}=E_{S i}(1-P)^{3}$ where $E_{s i}$ is the modulus of bulk silicon, $163 \mathrm{GPa}$ [32]. Compared to the shift for a bulk silicon vibrating beam $(P=0)$, the expected shift induced by adsorption for PS microbeams of porosity $P=73 \%$ is 50 times greater, indicting the significant improvement possible with porous MEMS. 


\subsection{Vapour sensing in static mode}

Both released PS microcantilever and doubly clamped microbeams were tested via the static deflection read-out mode for the ability to sense solvent vapour. The evolution of the deflection height $(\delta)$ during the testing of both types of microbeam is plotted in Fig. 8(a)-(b). The cantilever had dimensions of $(L=175 \mu \mathrm{m}) \times(W=30 \mu \mathrm{m}) \times(t=2.5 \mu \mathrm{m})$, and the deflection $\delta$ was measured at its tip. The doubly clamped microbeam had dimensions of $(L=300 \mu \mathrm{m}) \times(W=30 \mu \mathrm{m}) \times(t=2.5 \mu \mathrm{m})$, and the height was measured at the centre of the microbeam. As shown in the plots, both the cantilever and doubly clamped microbeam exhibited a significant height change after being exposed to isopropanol for $15 \mathrm{~min}$, with a maximum deflection of $6.5 \mu \mathrm{m}$ for the cantilever and $0.6 \mu \mathrm{m}$ for the doubly clamped microbeam. The cantilever deflection measurements shown in Fig. 8a show an exceptional deflection of $3.7 \%$ of the beam length from a single exposure, and sensitivity of $5.9 \times 10^{-3} \mu \mathrm{m} / \mathrm{ppm}$ at vapour density of $1100 \mathrm{ppm}$. Isopropanol has a relatively low surface tension of $0.023 \mathrm{~N} / \mathrm{m}$, and at the concentrations used here, is expected to completely cover the surface of the beam. By way of comparison, studies using myoglobin protein which produced a large surface tension of $0.05 \mathrm{~N} / \mathrm{m}$ resulted in only $0.89 \mu \mathrm{m}$ deflection in extremely long $(500 \mu \mathrm{m})$ and wide $(100 \mu \mathrm{m})$ beams $[33,34]$. Even with considerable alteration of this geometry, a simulated deflection of only $1.62 \mu \mathrm{m}$ was estimated under similar conditions [34].

The high cantilever deflection is a key characteristic of these porous structures and is due to the stress gradient change within the porous microstructures, induced by the adsorption of the isopropanol. Both the very low Young's modulus (compared with traditional MEMS materials such as silicon and $\mathrm{SiN}_{\mathrm{x}}$ ) and the large surface area contribute to the high sensitivity. To understand this, consider the deflection $\delta(L)$ at the cantilever end given by [35]:

$$
\delta(L)=\frac{M L^{2}}{2 E I}
$$


where the $M$ is a concentrated end bending moment (due to stress gradient), $E$ is the Young's modulus and $I$ is the moment of inertia of a beam given by $I=W t^{3} / 12$. Using the Young's modulus for porous silicon given by $E_{P S}=E_{s i}(1-P)^{3}$ the deflection can be written as:

$\delta=\frac{6 M L^{2}}{E_{S i}(1-P)^{3} W t^{3}}$

Compared with a silicon microcantilever $(P=0)$, our porous silicon microcantilever with a porosity of $P=73 \%$ is expected to have 50 -times greater deflection, making any slight changes in analyte adsorption considerably easier to detect. This analysis also suggest that both static and dynamic mode sensing achieve the same order of improvement in sensitivity through the use of porous MEMS. This significant increase in deflection does not take into account the additional increase in deflection due to the larger surface area available in the porous beams. The available surface-area-to-mass of a bulk silicon microcantilever of the dimensions used in Fig. 8(a) would be $0.38 \mathrm{~m}^{2} / \mathrm{g}$, compared to an estimated surface area greater than $500 \mathrm{~m}^{2} / \mathrm{g}$ for porous silicon [36]. The deflection observed in our porous silicon MEMS cantilever is equivalent to an end moment of $M=55 \mu \mathrm{N} \cdot \mu \mathrm{m}$ using Eq. (4). For comparison with the analysis by Ansari et al. [34], the estimated end-moment in an equivalent bulk cantilever, due to the low surface tension of $0.023 \mathrm{~N} / \mathrm{m}$ for isopropanol, is only $0.83 \mu \mathrm{N} \cdot \mu \mathrm{m}$. Hence, the induced moment in the porous structure is larger by a factor of 65 , consistent with our estimation of greater than 50-times deflection in the PS-MEMS cantilevers. As such the sensitivity of porous silicon sensors, supported by our experimental data, is extremely high and raised questions regarding stability and repeatability of the PS-based MEMS sensors. Therefore longer term studies were undertaken.

After the PS microstructures had been exposed to air for considerable time (up to 7 days), the heights were found to decrease by only a very small amount and they did not return to their 
original undeflected states. This suggests that the change caused by the isopropanol adsorption results in a permanent change to the material. Between 4 hours to 48 hours exposure to air, the microbeam height change was less than $0.8 \mu \mathrm{m}$, and between 48 hours to 7 days exposure to air, approximately $0.2 \mu \mathrm{m}$ height change was measured. This indicates that the change in the film properties caused by the vapour adsorption is much more significant than any change due to the ambient exposure, such as oxidation or temperature induced changes. Compared to dynamic mode operation which depends on residual stress that can alter significantly over time if the films are not passivated, static mode measurements depend on stress gradient which appears much less susceptible to change as a result of oxidation where the oxidation is uniform throughout the film.

In addition, these results show the height change after the isopropanol exposure is mainly due to the solvent but not other factors. An acetone sensing experiment was subsequently carried out on the same cantilever, which showed similar results to the isopropanol test but achieved a maximum deflection of only $4.7 \mu \mathrm{m}$. Interestingly the surface tension of acetone is $0.025 \mathrm{~N} / \mathrm{m}$, which is comparable to isopropanol. The lower measured deflection may be due to the lower affinity of acetone to form hydrogen bonds than isopropanol [37], or more rapid vapourisation due to the 5 times higher vapour pressure of acetone compared to isopropanol at room temperature.

To investigate the repeatability of sensing with the PS cantilever of size $175 \mu \mathrm{m} \times 30 \mu \mathrm{m} \times 2.5 \mu \mathrm{m}$, the sensing test as described before was performed multiple times. After each period of vapour exposure, the height change achieved by the cantilever was recorded, and subsequently the sample was rested in air for 7 days to ensure the height of the microbeam had reached steady state. The height changes for each test are plotted in Fig. 9(a)-(c). As seen in Fig. 9(a), the magnitude of the net step height change (steady-state value - initial 
value) of the PS cantilever decreased after each sensing test, becoming zero after the $4^{\text {th }}$ test and $5^{\text {th }}$ test. This indicates that in the steady state the microbeam had reached the limit of permanent height change due to the vapour adsorption and therefore no further structural change occurred. Importantly, the change due to the vapour adsorption was significantly greater than any change that occurred over the intervening 7-day period, suggesting the sensor was extremely stable. Fig. 9(b) also shows that for the $4^{\text {th }}$ and $5^{\text {th }}$ tests, exactly the same step height change (downward deflection) of $1.4 \mu \mathrm{m}$ initially occurred, followed by a return to the same steady state position as after the $3^{\text {rd }}$ test, after evaporation of the adsorbed vapour. This can also be seen from the cantilever height change in the first hour of each tests as shown in Fig. 9(c), indicating the microbeam reached a state of highly repeatable performance for vapour sensing. The most likely cause of the downward, repeatable, net-zero height change is the contribution from the increased mass and surface tension caused by the vapour adsorption (and then desorption/evaporation) in each of these latter tests. For example, assuming the entire air volume of the beam with $73 \%$ porosity is filled with isopropanol, the change in mass is approximately $10 \mathrm{ng}$ so that the distributed force along the beam would account for $20 \%$ of the downward deflection. This indicates that unlike for the case for MEMS fabricated from bulk materials with large modulus where the effect of mass is negligible, the same is not true for porous MEMS. However, the mechanism that leads to initial, permanent net cantilever height change which then saturates is still under investigation and outside the scope of this report.

The results indicate nonetheless that monitoring deflections in the PS-MEMS cantilever height offers great promise for measuring very small mass changes. It provides significant opportunities for improving the sensitivity in ultra-small concentration sensing, and proves that released PS microstructures fabricated in this work could be applied as chemical and gas sensors. 


\section{CONCLUSION}

Resonant vibration measurements in dynamic mode and vapour sensing in static mode were carried out on released all-PS microbeams. The highest ever reported resonant frequencies (5$250 \mathrm{kHz}$ ) for PS microbeams were measured. Residual stress and Young's modulus of PS films were extracted from the resonant frequency measurements. A vapour density of $1100 \mathrm{ppm}$ was clearly detected with up to $6.5 \mu \mathrm{m}$ of deflection which was $3.7 \%$ of the beam length, and found to be stable for many days after exposure. This new, scalable MEMS platform provide significant opportunities for low limit of detection, high sensitivity chemical and gas sensing.

\section{ACKNOWLEDGEMENT}

This work was supported by the UWA Scholarships for International Research Fees, University Postgraduate Award and Ad Hoc Postgraduate Scholarship. The authors acknowledge the support from the Australian Research Council, Western Australian Node of the Australian National Fabrication Facility, and the Office of Science of the WA State Government. We acknowledge the Australian Microscopy \& Microanalysis Research Facility at the Centre for Microscopy, Characterisation \& Analysis, The University of Western Australia, a facility funded by the University, State and Commonwealth Governments. This work was support by the Australia Research Council Discovery Project [grant number DP170104266].

\section{REFERENCES}

[1] A. UHL $\mathbb{R}$, EU BCIROLYIC SHAPING OF GHRMANIUM AND SILICON, BHL SYSTEM TECHNICAL JOURNA, 35(1956) 333-7.

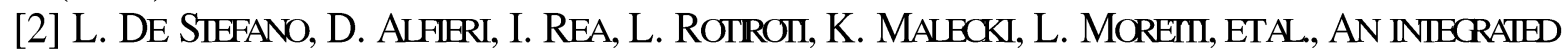
PRESSURE-DRIVEN MICROSYSTEM BASED ON POROUS SILCONFOROPIICAL MONIIORING OF GASEOUS AND LQUID SUBSTANCES, PHYSICASTATUS SO IDI (A), 204(2007) 1459-63. 
[3] B.H. King, A.M. RuMINSKI, J.L. SNYDER, M.J. SAILOR, OPTICAL-FIBER-MOUNIED POROUS SILICON PHOTONIC CRYSTALSFOR SENSING ORGANIC VAPOR BREAKIHROUGH IN ACTIVATIEDCARBON, ADVANCFD MATHRIALS, 19(2007) 4530-4.

[4] M. Lai, G.M. SRIDHARAN, G. Parish, S. Bhattacharya, A. KeAting, Mutullayer POROUS SILICON DIFRACTION GRATINGS OPERATING INTHE INRRARED, NANOSCALE RESEARCH LEIIIRS, 7(2012) 645.

[5] I. REA, M. IODICE, G. COPPOLA, I. RENDINA, A. MARINO, L. DE StEFANO, A POROUS SIICON-BASED BRAGG GRATING WAVEGUIDE SENSORFORCHEMICAL MONIIORING, SENSORS AND ACTUATCRS B: CHEMICAL, 139(2009) 39-43.

[6] V. VRKoslaV, I. JelíneK, T. TROJan, J. Jindřich, J. Dian, Porous sil icon with $\beta$-CyCODEXIRIN MODIFIED SURFACE FOR PHOTOUMINESCENCE SENSING OFORGANIC MOLBCUES IN GAS ANDLIQUID PHASE, PHYSICA E: LOW-DIMENSIONAL SYSIEMS AND NANOSTRUCIURES, 38(2007) 200-4.

[7] G. BARILARO, A. DiligenII, G. Marola, L.M. StRAMBINI, A SILICON GrySTAIINERESISTCRWIIHAN ADSORBING POROUSLAYBR AS GAS SENSOR, SENSORS AND ACTUATCRS B: CHEMICAL, 105(2005) 278-82. [8] C. WONGMANHROD, S. ZANGOOIE, H. ARWIN, DEIHRMINATION OF PORE SIZE DISIRIBUTION AND SURFACE AREA OFTHIN POROUS SILICONLAYBRS BY SPECTROSCOPIC HUIPSOMEIRY, APPLIED SURFACE SCIENCE, 172(2001) 117-25.

[9] S. CHAN, S.R. HORNER, P.M. FAUCHET, B.L. MIIER, IDENIIFICATIONOFGRAMNEGATIVE BACIHIA USING NANOSCALE SILICON MICROCAVIIIES, JOURNALOFTHE AMERICAN CHEMICALSOCIETY, 123(2001) 11797-8.

[10] F.A. HARRAZ, POROUS SILICONCHEMICALSENSORS AND BIOSENSORS: A REVIEW, SENSORS AND ACTUATCRS B: CHEMICAL, 202(2014) 897-912.

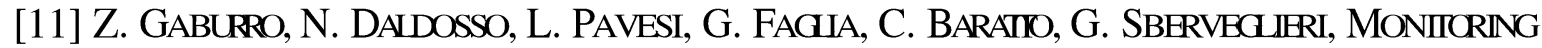
PENEIRATION OFEIHANOL IN A POROUS SULCON MICROCAVIIY BY PHOTOUMINESCENCE INIHRHROMEIRY, APPLIED PHYSICS LETIHR, 78(2001) 3744-6.

[12] I.A. LEVIISKY, POROUS SILICON SIRUCTURES AS OPTICALGAS SENSORS, SENSORS, 15(2015) 19968-91. [13] E.V. ASTROVA, V.A. TOLMACHEV, EFFECIIVERHRACIVE INDEX ANDCOMPOSIION OF OXIDIZED POROUS SILICONFILMS, MATHRIALS SCIENCE AND ENGINEHRING: B, 69(2000) 142-8.

[14] P.A. SNOW, E.K. SQURE, P.S.J. RUSSHL, L.T. CANHAM, V APOR SENSINGUSINGTHEOPTICAL PROPERIIES OF POROUS SILICON BRAGG MIRRORS, JOURNALOF APPLIED PHYSICS, 86(1999) 1781-4.

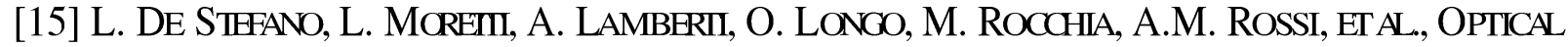
SENSORSFOR VAPORS, LLQUIDS, AND BIOLOGICAL MOLBCUES BASED ON POROUS SLICONTBCHNOLOGY, NANOIBCHNOOGY, IEEE TRANSACTIONS ON, 3(2004) 49-54.

[16] E. GuHHRMain, V. Lysenko, R. OrOBIChOUK, T. Benyatiou, S. ROUX, A. PHONNET, eT AL, BRAGG SURFACE WAVE DEVICE BASED ON POROUS SILICON AND IIS APPLICATIONFORSENSING, APPLIED PHYSICSLEIIHRS, 90(2007) 241116.

[17] E. Lorenzo, C.J. Oton, N.E. Capuj, M. Ghulnyan, D. NaVArro-Urrios, Z. Gaburro, et al, POROUS SILICON-BASEDRUGATEFILTHRS, APPL OPT, 44(2005) 5415-21.

[18] V. MuIONI, Z. GABURRO, L. PAVESI, POROUS SIlICON MICROCAVITIES AS OPTICALAND HECTRICAL CHEMICAL SENSORS, PHYSICA STATUS SOLIDI A, 182(2000) 479-84.

[19] H. OUYANG, C.C. STRIEMER, P.M. FAUCHET, QUANITATIVE ANALYSIS OFTHE SENSITIVIIY OF POROUS SILICON OPTICALBIOSENSORS, APPLIED PHYSICS LETIERS, 88(2006) 163108.

[20] N.V. LAKRIK, M.J. SEPANIAK, P.G. DATSKOS, CANTIEVERTRANSDUCERS AS A PLATFCRMFORCHEMICAL AND BIOLOGICALSENSORS, REVIEW OF SCIENIIFIC INSIRUMENIS, 75(2004) 2229-53.

[21] Y.T. Yang, C. CAUIEGARI, X.L. FenG, K.L. EKINCI, M.L. ROUKES, ZEPIOCRAM-SCAIE NANOMECHANICAL MASS SENSING, NANO LETIHRS, 6(2006) 583-6. 
[22] X. Sun, A. KEATING, G. PARISH, RHEASED MICROMACHINED BEAMS UTUZZINGLATHRALY UNIFORM POROSITY POROUS SILICON, NANOSCALE RESEARCH LETIHRS, 9(2014) 426.

[23] X. SUN, G. PARISH, A. KEATING, FABRICATION OFUNIFORM POROSITY, ALL-POROUS-SILICON MICROSTRUCTURES AND STRESS/STRESS GRADIENTCONIRC, JOLRNALOF MICROMECHANICS AND MICROENGINEHRING, 27(2017) 044001.

[24] R.E. FernandEZ, S. Stolyarova, A. ChadHA, E. BHATtACHARYA, Y. NEMIROVSKY, MEMS COMPOSIIE POROUS SILICON/POLYSILICONCANILEVER SENSORFORENHANCEDTRIGLYCBRIDES BIOSENSING, IEEE SENSORS JOURNA, 9(2009) 1660-6.

[25] G. PUIRINO, A HIGH PRECISION POSITION SENSITIVE DEIBCIIONTECHNOLOGY FOR MICRO-EIECIROMECHANICALSYSTEMS (MEMS) BASEDON AN OPIICALRESONANTCAVITY, PERIH: THE UNIVERSITY OF WESTHRN AUSIRALA; 2013.

[26] M. Lai, G. PARISH, Y. LiU, J.M. DHL A.J. KeATING, DEVELOPMENTOFAN ALKALINE-COMPATIBUE POROUS-SILICON PHOTOUIHOGRAPHIC PROCESS, JOURNALOF MICROHBCIROCHAMICALSYSIEMS, 20(2011) 418-23.

[27] E.B. MACRAB, VIBRATIONS OFHASTIC SYSTEMS: WIIH APPLICATIONSTO MEMS AND NEMS:

SPRINGER SCIENCE \& BUSINESS MEDIA; 2012.

[28] W. WEAVER JR, S.P. TIMOSHENKO, D.H. YOUNG, VIBRATION PROBLEMS IN ENGINEHRING: JOHN WIIEY \& SONS; 1990.

[29] L.M. ZhANG, D. UTTAMCHANDANI, B. CULSHAW, P. DOBSON, MEASUREMENTOF YOUNG'S MODUUS AND INIHRNALSTRESS IN SLLCON MICRORESONATCRS USING ARESONANTHREQUENCYTECHNIQUE, MEASUREMENT SCIENCE AND TBCHNOLOGY, 1(1990) 1343.

[30] L.M. Zhang, D. UtTamohandani, B. CUlshaW, P. DOBSON, MEASUREMENTOF Young's MOdUUS AND INIHRNALSIRESS IN SILICON MICRORESONATORS USING ARESONANTHREQUENCYTECHNIQUE, MEASEMENT SCIENCEANDTECHNOLOGY, 1(1990) 1343-6.

[31] X. SUN, A. KEATING, G. PARISH, STRESS CONIRCLOF POROUS SIUCONFLMS FOR

MICROHECIROMECHANICALSYSTEMS, MICROPOROUS AND MESOPOROUS MATHRIALS, $218(2015)$ 88-94. [32] C. POPU LARE, B. REMAKI, V. LySENKO, D. BARBIER, H. ARTMANN, T. PANNEK, ON MECHANICAL PROPERIIES OFNANOSIRUCTURED MESO-POROUS SILICON, APPLIED PHYSICS LETIHRS, 83(2003) 1370-2. [33] Y. ARNIZ, J.D. SEH IG, H.P. LANG, J. ZHANG, P. HUNZIKER, J.P. RAMSEYER, ET AL., LABH-HREE PROIEIN ASSAY BASED ON ANANOMECHANICALCANTIEVBR ARRAY, NANOIBCHNOLOGY, 14(2002) 86.

[34] M.Z. ANSARI, C. CHO, A SIUDY ON INCREASING SENSIIIVITY OFRECTANGULARMICROCANILEVERSUSED IN BIOSENSORS, SENSORS, 8(2008) 7530-44.

[35] M. TயU, L. Motooka, Cornhuus T., V.M. AiraKsinen, S. Franssila, M. Paulasto-KrockH, V. LINDROOS, MEMS/NEMS: HANDBOOK OF SILICON BASED MEMS MATHRIALSTECHNIQUES AND

TECHNOLOGIESAPPLICATIONS DESIGN METHODS, VOL. 4: SENSORS AND ACTUATCRS: El SEVIERSPRINGER SCIENCE \& BUSINESS MEDIA; 20152007.

[36] L. CANHAM, HANDBOOK OF POROUS SILICON, CHAM: SPRINGER; 2014.

[37] R.A.Y. JONES, PHYSICALAND MECHANISTIC ORGANIC CHEMISTRY: CAMBRIDGE UNIVERSITY PRESS; 1979.

FIGURE CAPTIONS:

Figure1: Cross sectional SEM images of meso-porous silicon. (a) PS film formed on Si substrate; (b) detailed pore size of PS film.

Figure 2: Angled view SEM images of released all-PS microbeams, beam voltage of $5 \mathrm{kV}$. (a) Doubly clamped microbeams; (b) cantilevers. 
Figure 3. Schematic of laser Doppler vibrometer system for resonant frequency measurement of the PS microbeams.

Figure 4. Schematic diagram of experimental configuration on optical profilometer stage for sensing of vapour with PS microbeams. (a) PS microbeam (cantilever) kept with a drop of liquid in the chamber, (b) chamber cover removed after completely evaporation of the liquid to allow beam deflection measurement.

Figure 5. Resonant frequency of PS microbeams with different length (L), measured under vacuum with a laser Doppler vibrometer, to show the read displacement (Dis.) with sweep in a frequency range. (a) $\mathrm{L}=200 \mu \mathrm{m}$, (b) $\mathrm{L}=250 \mu \mathrm{m}$, (c) $\mathrm{L}=300 \mu \mathrm{m}$, (d) $\mathrm{L}=400 \mu \mathrm{m}$.

Figure 6. Comparison of measured results and theoretical model of frequency of PS microbeams.

Figure 7. The relationship between $L^{-2}$ (inverse beam length squared) and the net effective stress determined from resonant frequency measurements of doubly clamped PS microbeams. Experimental data (red circles) is fit with a linear regression for all beam lengths shorter than 350 $\mu \mathrm{m}\left(\mathrm{L}^{-2}>8 \times 10^{-6} \mu \mathrm{m}^{-2}\right)$, from which the compressive stress could be determined. The stress corresponding to the Euler Buckling limit is also shown (red solid line). The compressive stress in larger beams is affected by the Euler Bucking Limit giving rise to large uncertainties in the region $\mathrm{L}^{-2}<8 \times 10^{-6} \mu \mathrm{m}^{-2}$ ).

Figure 8. PS microbeam height evolution after isopropanol adsorption and subsequent exposure to air. (a) Cantilever tip height change; cantilever length of $175 \mu \mathrm{m}$. (b) Doubly clamped microbeam centre height change; microbeam length of $300 \mu \mathrm{m}$.

Figure 9. Repeated tests on PS cantilever for isopropanol sensing. (a) Change in cantilever tip height over time for the duration of each test, (b) the maximum step height change after exposure to isopropanol in each test, (c) comparison of PS cantilever height change for the first hour in each test. 


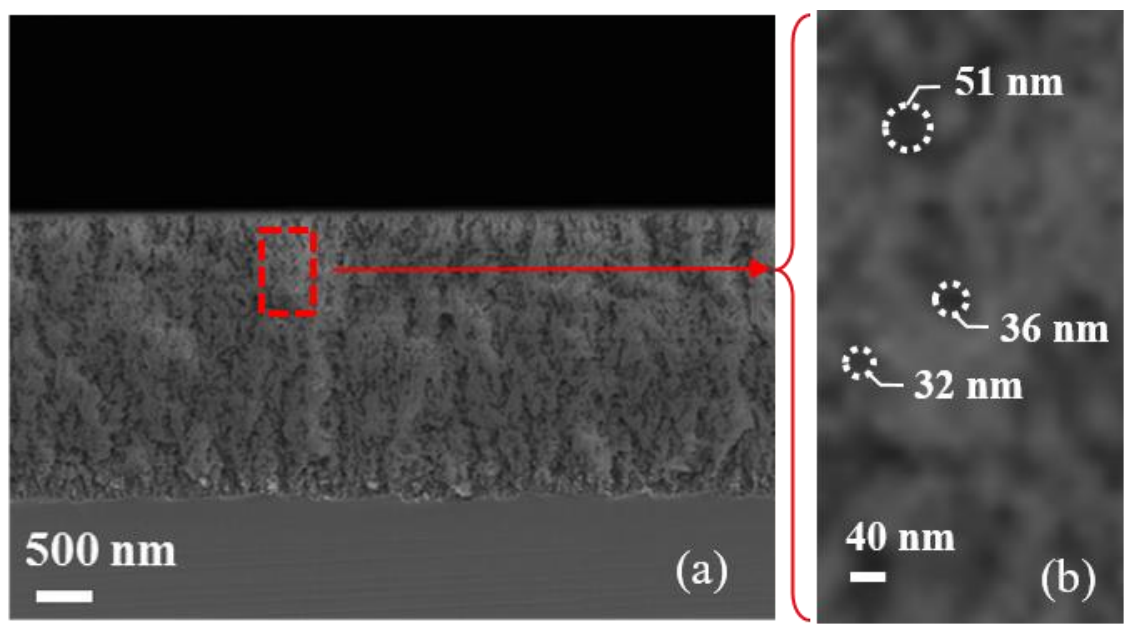


Si substrate PS anchor Doubly clamped PS microbeam

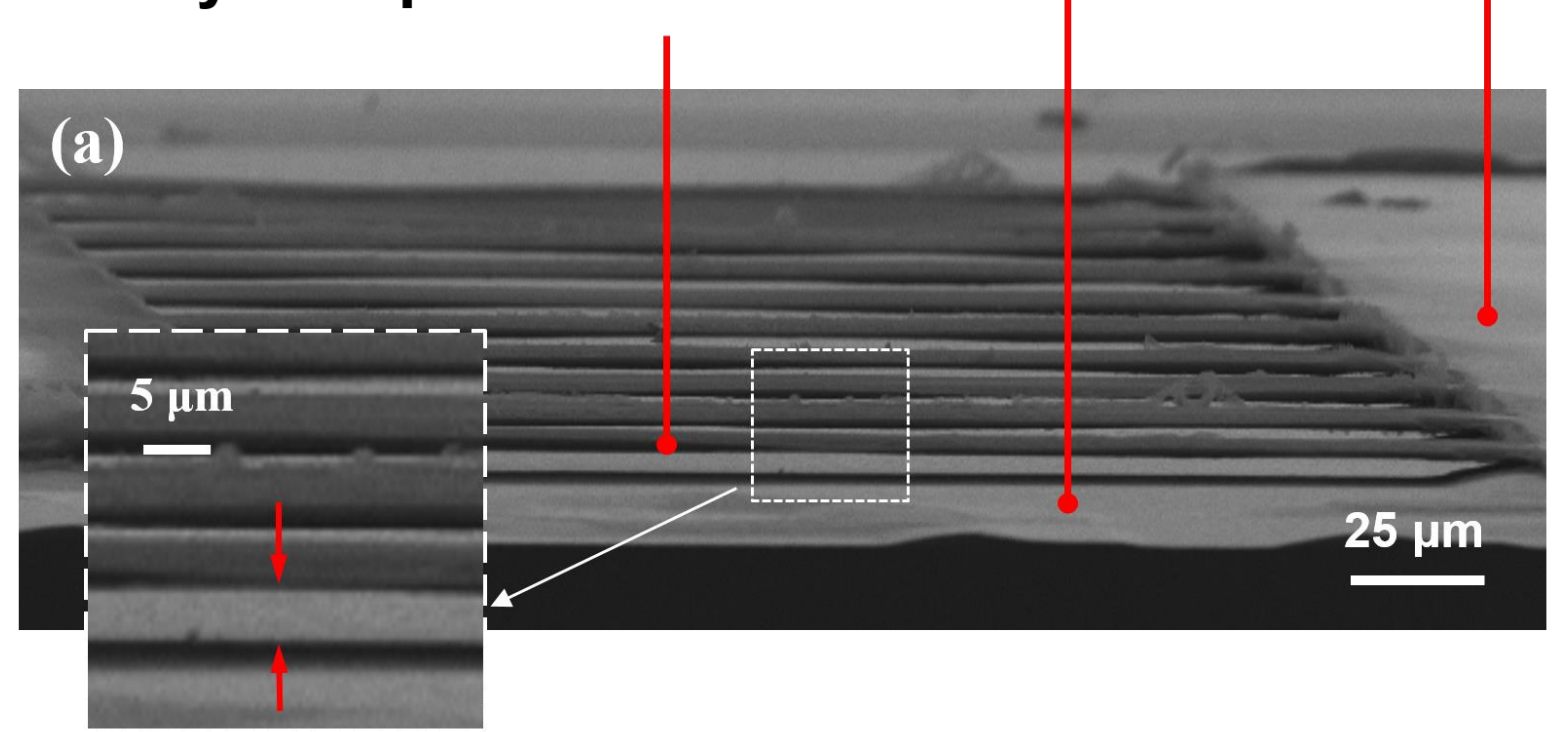

Air gap

(b) 


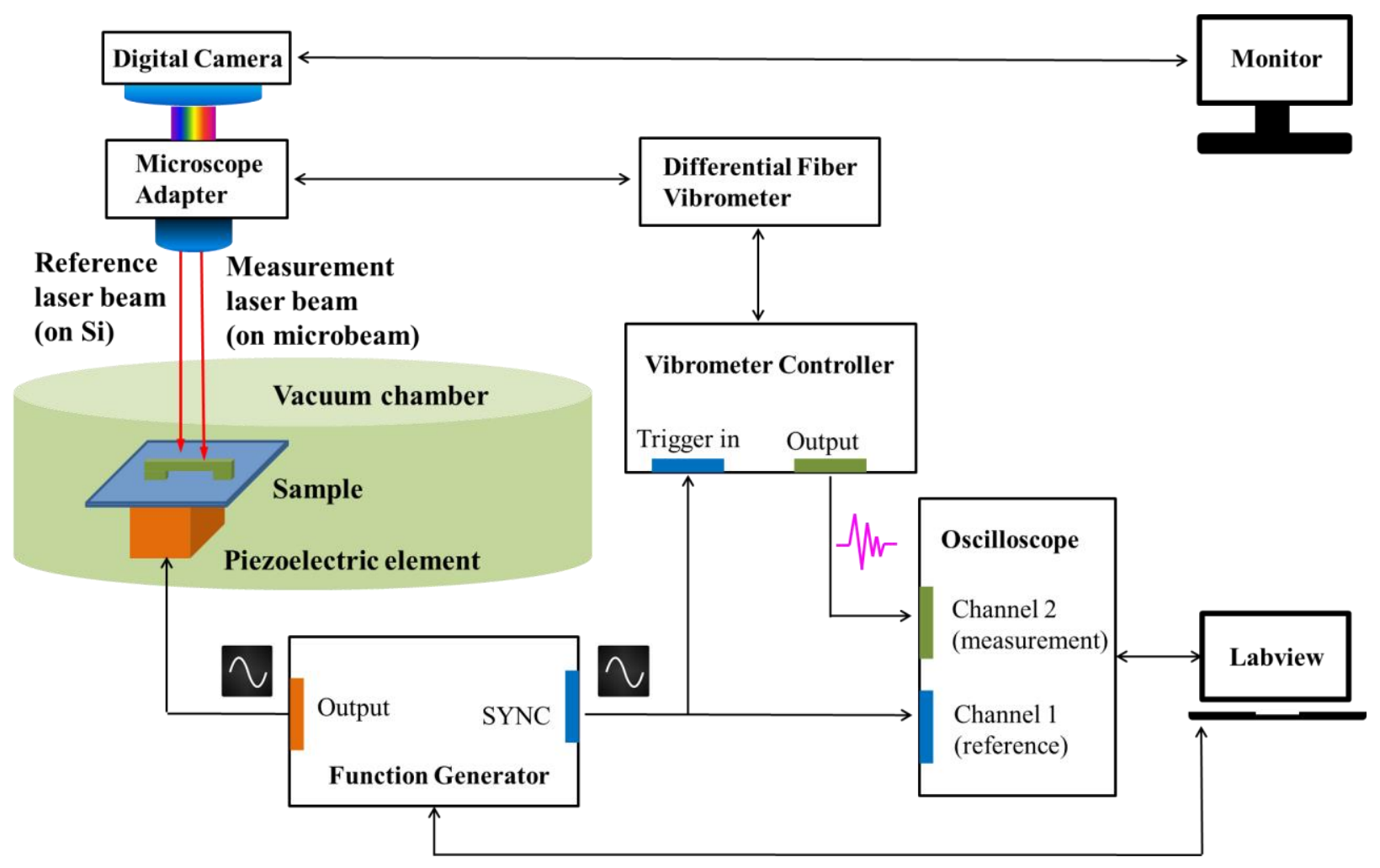


A drop of liquid

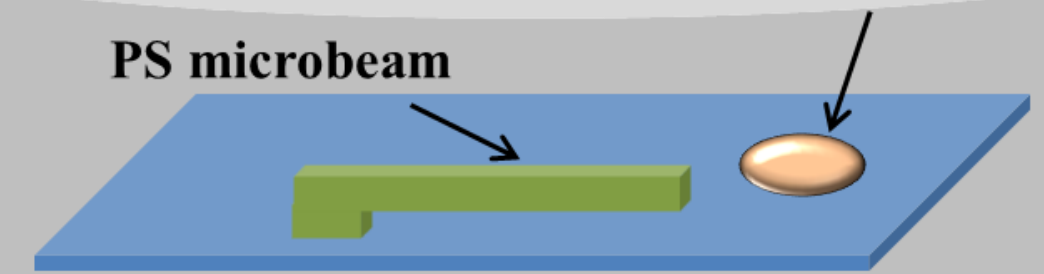

Chamber

(a)

(b)

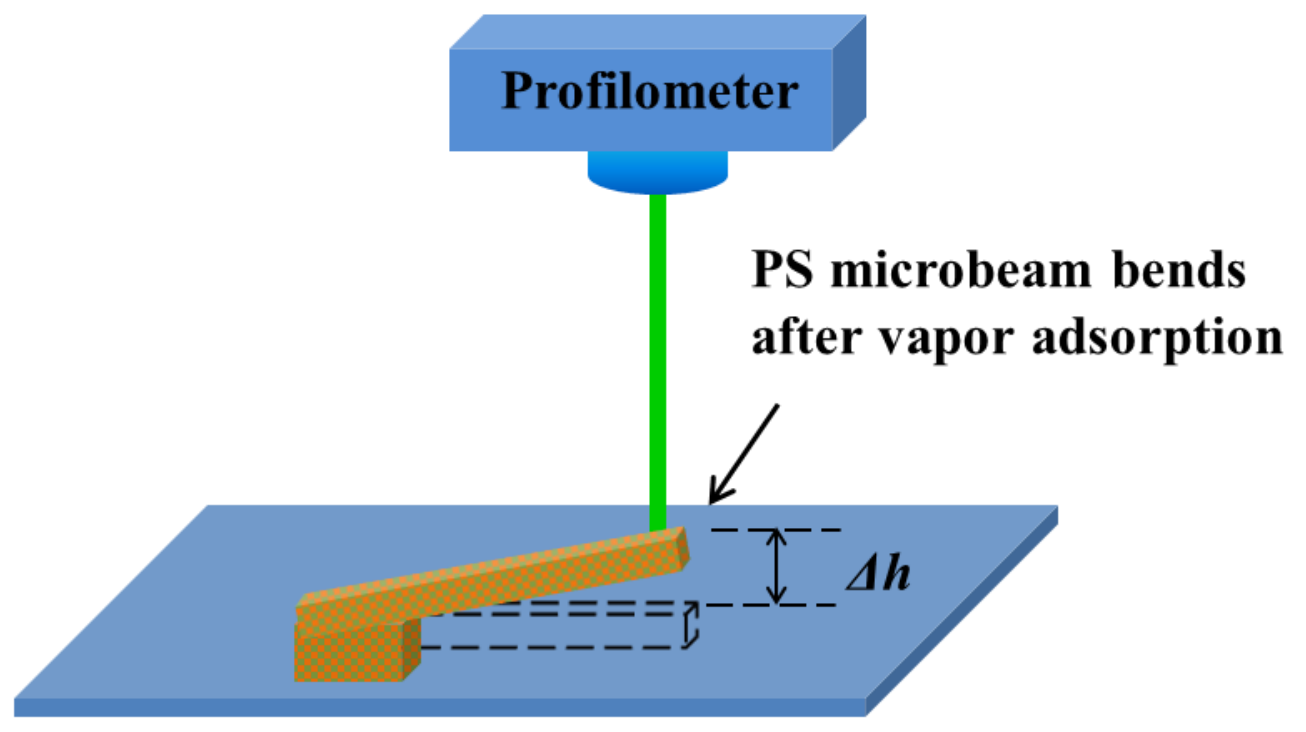




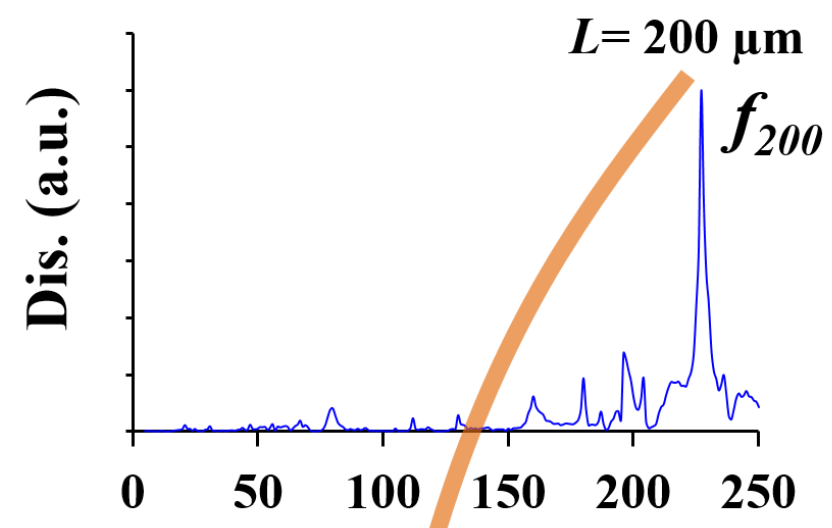

(a)

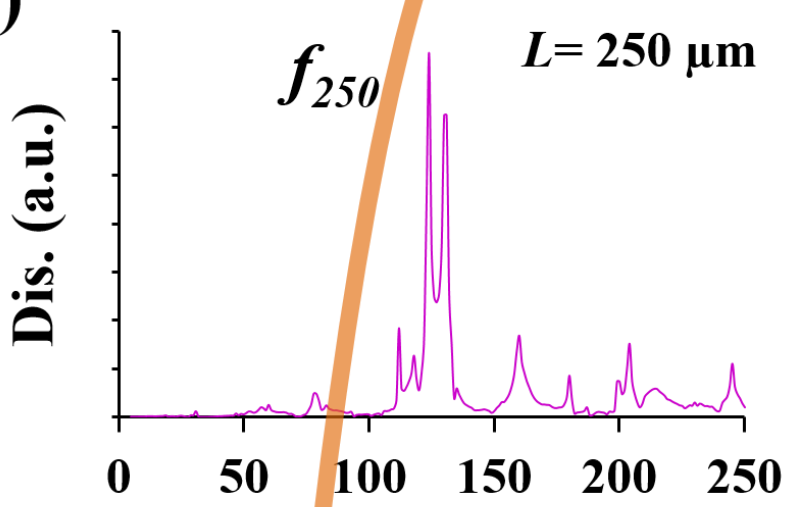

(b)

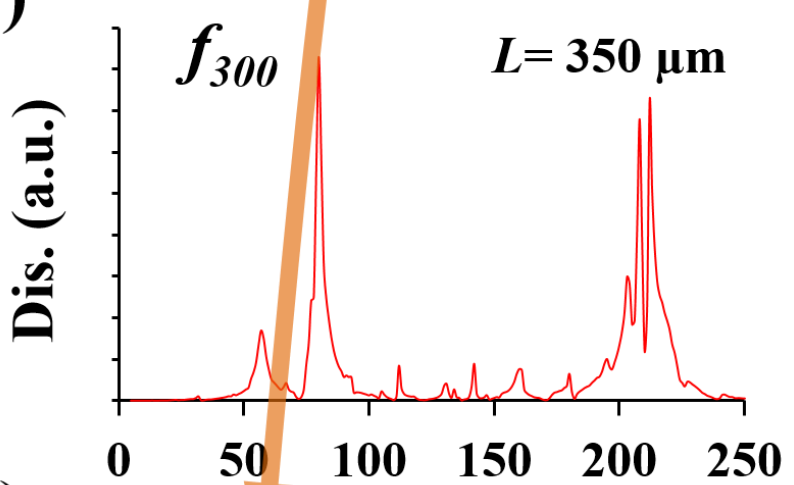

(c)

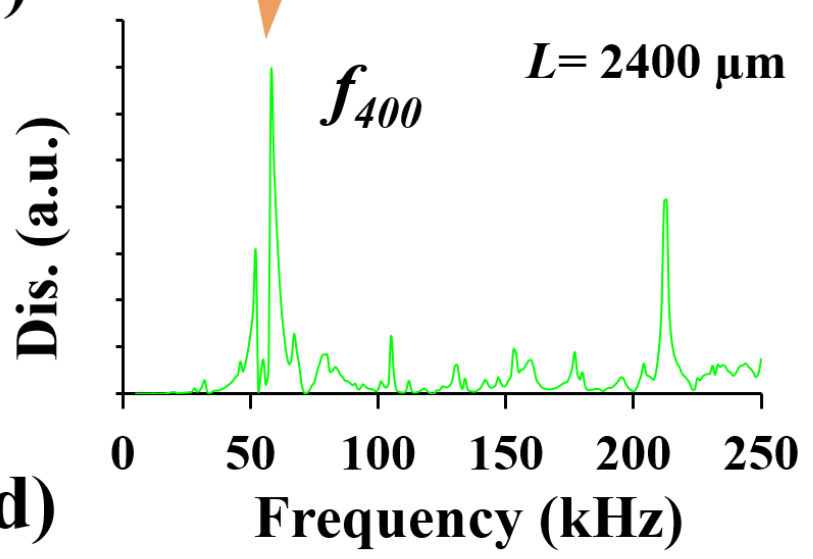




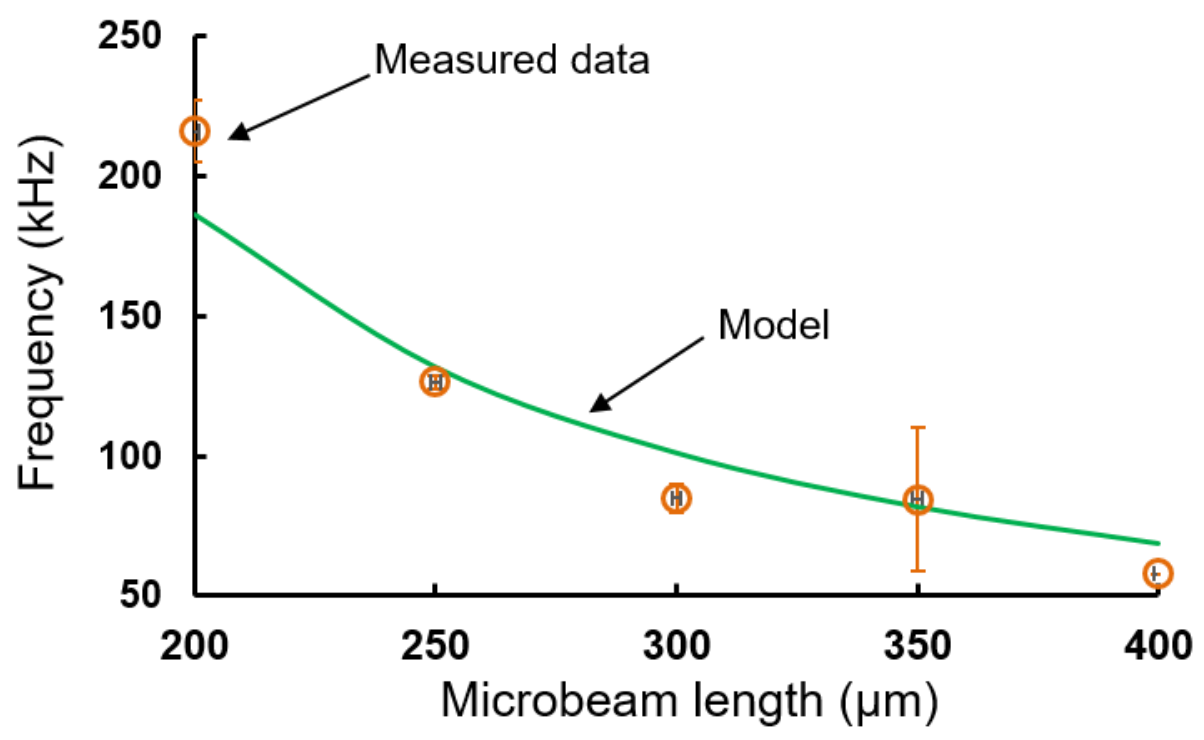




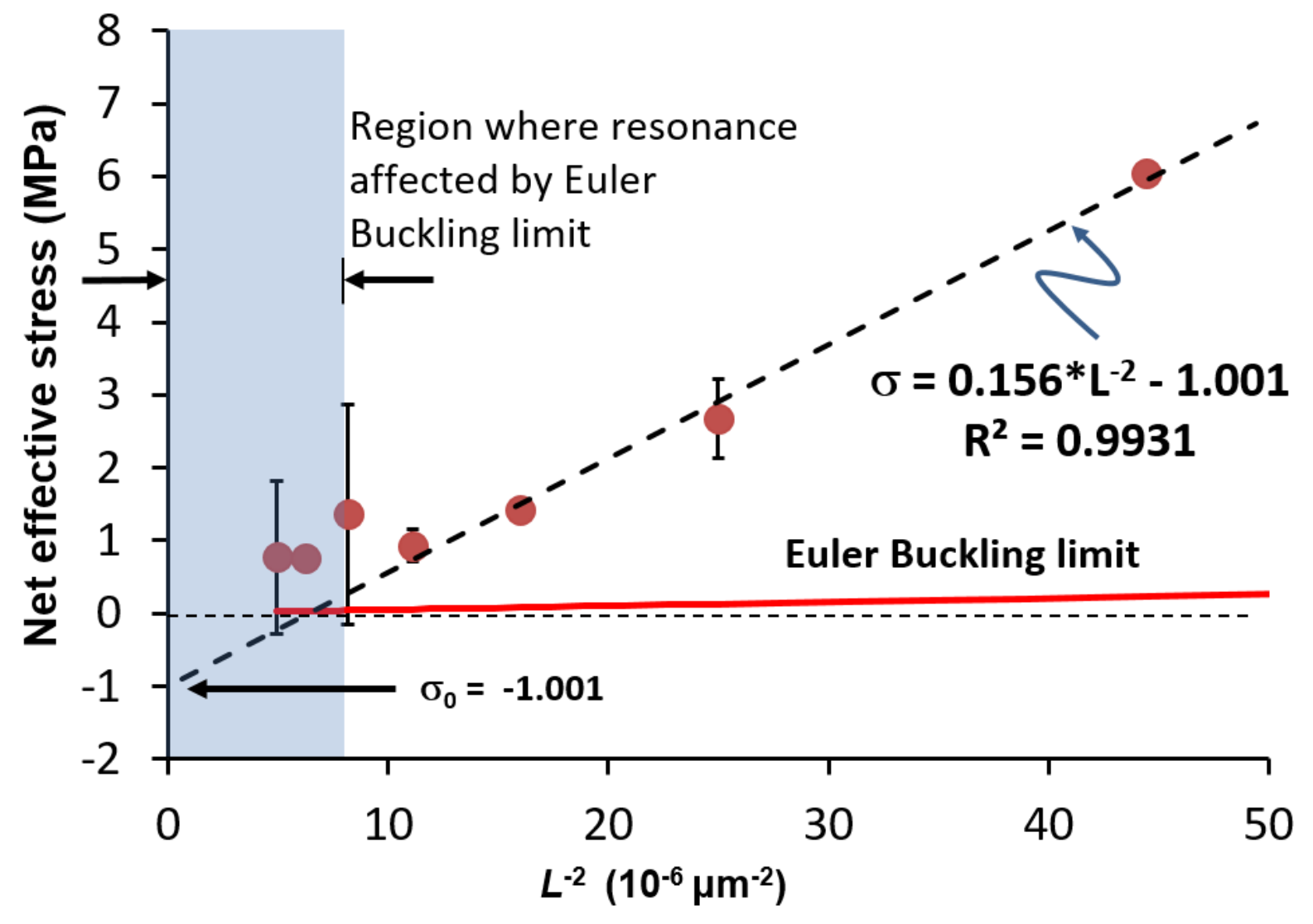




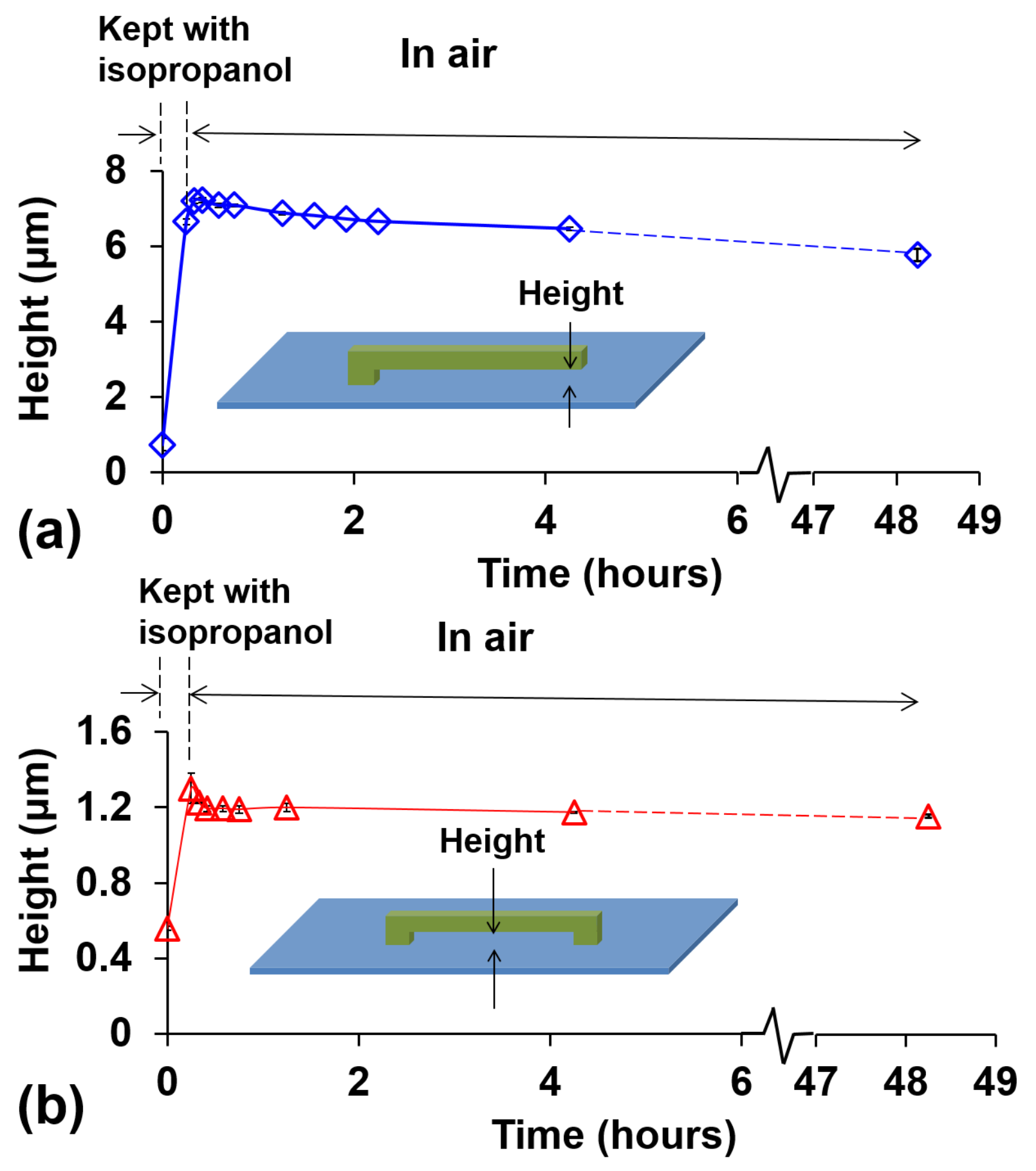




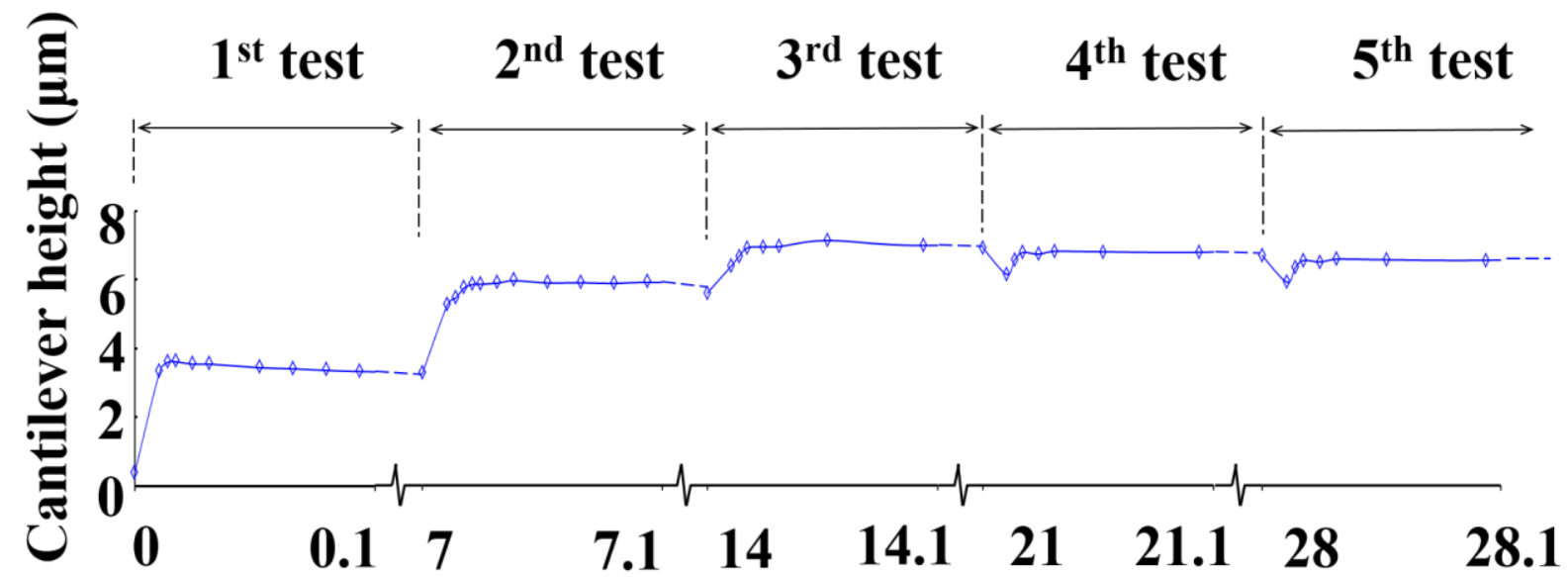

(a)

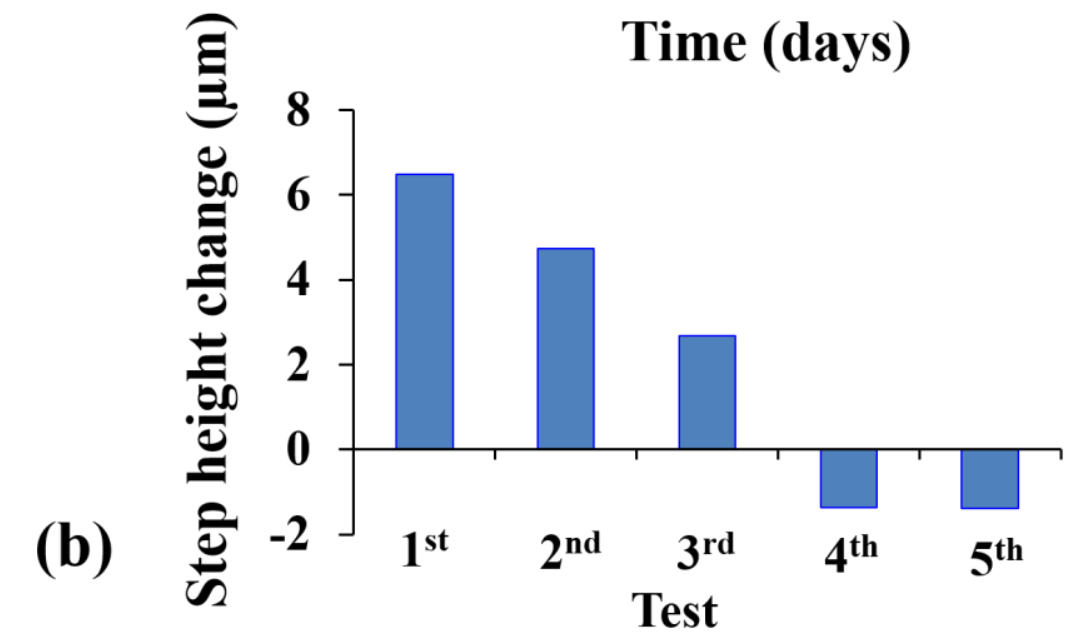

\section{Kept with}

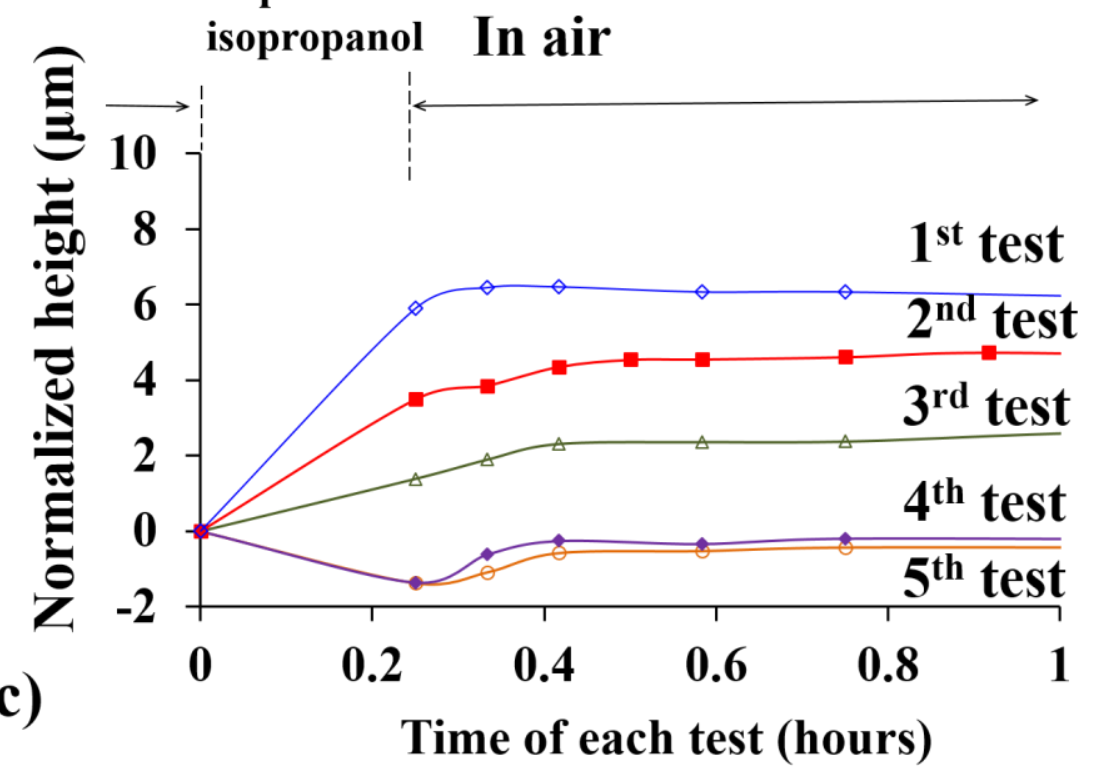

